\title{
Lack of evidence for the pathogenic role of iron and HFE gene mutations in Brazilian patients with nonalcoholic steatohepatitis
}

\footnotetext{
M.M. Deguti ${ }^{1}$,

A.M. Sipahi $i^{1,3}$,

L.C.C. Gayotto ${ }^{2}$,

S.A. Palácios ${ }^{5}$,

P.L. Bittencourt ${ }^{1}$,

A.C. Goldberg 5 ,

A.A. Laudanna ${ }^{1}$,

F.J. Carrilho ${ }^{1}$ and

E.L.R. Cançado ${ }^{1,4}$
}

\author{
Departamentos de ${ }^{1}$ Gastroenterologia and ${ }^{2}$ Patologia, \\ Laboratórios de Investigação Médica ${ }^{3}$ LIM-07 and ${ }^{4}$ LIM-06, \\ Faculdade de Medicina, and ${ }^{5}$ Laboratório de Imunologia do Transplante, \\ Instituto do Coração, Universidade de São Paulo, São Paulo, SP, Brasil
}

\begin{abstract}
Correspondence
M.M. Deguti

Departamento de Gastroenterologia FM, USP

Av. Enéas C. Aguiar, 255, S. 9159

01246-903 São Paulo, SP

Brasil

Fax: +55-11-5584-5122

E-mail: marta.deguti@uol.com.br

M.M. Deguti was supported by CNPq (Grant No. 135303/1999-0).

Publication supported by FAPESP.
\end{abstract}

Received July 18, 2002

Accepted April 17, 2003

\begin{abstract}
The hypothesis of the role of iron overload associated with HFE gene mutations in the pathogenesis of nonalcoholic steatohepatitis (NASH) has been raised in recent years. In the present study, biochemical and histopathological evidence of iron overload and HFE mutations was investigated in NASH patients. Thirty-two NASH patients, 19 females (59\%), average 49.2 years, $72 \%$ Caucasians, $12 \%$ Mulattoes and $12 \%$ Asians, were submitted to serum aminotransferase and iron profile determinations. Liver biopsies were analyzed for necroinflammatory activity, architectural damage and iron deposition. In 31 of the patients, C282Y and H63D mutations were tested by PCR-RFLP. Alanine aminotransferase levels were increased in 30 patients, $2.42 \pm 1.12$ times the upper normal limit on average. Serum iron concentration, transferrin saturation and ferritin averages were $99.4 \pm 31.3 \mathrm{~g} / \mathrm{dl}, 33.1$ $\pm 12.7 \%$ and $219.8 \pm 163.8 \mu \mathrm{g} / \mathrm{dl}$, respectively, corresponding to normal values in $93.5,68.7$ and $78.1 \%$ of the patients. Hepatic siderosis was observed in three patients and was not associated with architectural damage $(\mathrm{P}=0.53)$ or with necroinflammatory activity $(\mathrm{P}=0.27)$. The allelic frequencies $(\mathrm{N}=31)$ found were 1.6 and $14.1 \%$ for $\mathrm{C} 282 \mathrm{Y}$ and $\mathrm{H} 63 \mathrm{D}$, respectively, which were compatible with those described for the local population. In conclusion, no evidence of an association of hepatic iron overload and HFE mutations with NASH was found. Brazilian NASH patients comprise a heterogeneous group with many associated conditions such as hyperinsulinism, environmental hepatotoxin exposure and drugs, but not hepatic iron overload, and their disease susceptibility could be related to genetic and environmental features other than $H F E$ mutations.
\end{abstract}

Key words - Fatty liver - Nonalcoholic steatohepatitis - Iron overload - HFE gene - Alanine aminotransferase A Alanine aminotransferase 


\section{Introduction}

Nonalcoholic steatohepatitis (NASH) was designated as such by Ludwig et al. in 1980 (1), and has been increasingly recognized as one of the most frequent diagnoses by hepatologists (2). Early studies (1-6) described NASH mainly in obese, middle-aged women, often associated with diabetes mellitus and hyperlipidemia. However, in recent years, other investigators (7-10) have found evidence of NASH association with male, nonobese, nondiabetic patients and with liver iron overload, which led to the hypothesis of iron playing a role in NASH pathogenesis.

The identification of the hereditary hemochromatosis HFE gene (11) on chromosome 6 and its $845 \mathrm{G} \rightarrow \mathrm{A}(\mathrm{C} 282 \mathrm{Y})$ and $187 \mathrm{C} \rightarrow \mathrm{G}$ (H63D) mutations has enabled further investigation of this aspect based on the knowledge that compound heterozygotes $(\mathrm{C} 282 \mathrm{Y} /$ H63D) and H63D homozygotes may have a mild or moderate iron overload (12). However, more recently, Gochee et al. (13) demonstrated that the presence of H63D does not result in significant iron overload, and that this mutation is not clinically significant in the absence of the $\mathrm{C} 282 \mathrm{Y}$ mutation.

George et al. (14) found that the $\mathrm{C} 282 \mathrm{Y}$ mutation of the $H F E$ gene was significantly associated with the degree of iron staining, hepatic iron concentration and liver damage in Caucasian NASH patients from Australia. Bonkovsky et al. $(15,16)$ expanded this concept by identifying both $\mathrm{C} 282 \mathrm{Y}$ and H63D which were significantly related to NASH in North Americans. In view of these data, the aim of the present study was to investigate the evidence of iron overload and the prevalence of $\mathrm{C} 282 \mathrm{Y}$ and $\mathrm{H} 63 \mathrm{D}$ mutations among NASH patients from São Paulo, SP, Brazil.

\section{Patients and Methods}

\section{Cohort of patients}

Thirty-two patients who fulfilled the diag- nostic criteria of NASH were enrolled in this study. NASH was defined histopathologically as macrovesicular steatosis, lobular inflammation and perivenular fibrosis morphologically indistinguishable from alcoholic disease in subjects whose alcohol consumption was less than $20 \mathrm{~g} /$ day. This study was approved by the local Ethics Committee and was performed according to the guidelines of the Helsinki declaration. Informed consent was obtained from each patient included in the study.

The initial database consisted of 112 patients suspected of having NASH who had been attended at the Gastroenterology Outpatient Clinic in the last 18 months. Suspicion of NASH was based on findings of a steatotic aspect of the liver by ultrasonography, serum aminotransferase elevation and negative serology for hepatitis $\mathrm{B}$ and $\mathrm{C}$ virus (HBsAg and anti-HCV antibody by the ELISA 3 test) in patients who denied alcohol consumption at hospital admission. All patients were evaluated by the same physician (M.M. Deguti) and received oral and written information about this protocol, with emphasis on the importance of providing reliable information. Patients with obesity (body mass index $\geq 30 \mathrm{~kg} / \mathrm{m}^{2}$ ), diabetes mellitus type 2 or hyperlipidemia (cholesterolemia or triglyceridemia $\geq 200 \mathrm{mg} / \mathrm{dl}$ after a $12-\mathrm{h}$ fast) were strongly urged to follow appropriate diets and physical exercise programs, and those who were using potentially hepatotoxic drugs were asked to discontinue them. The values of serum transaminases of 24 patients returned to normal levels within six months after taking these measures and these patients were not submitted to liver biopsies. Twenty-three subjects were excluded because they had not stated their actual alcohol consumption initially. Nine patients refused a liver biopsy and 24 had histopathological diagnoses other than steatohepatitis (nonspecific changes with focal liver cell regeneration, steatosis, and cirrhosis without an etiological marker). The remaining 32 patients participated in the study. 


\section{Methods}

Serum alanine aminotransferase, iron, transferrin saturation and ferritin levels were obtained at the time of liver biopsy.

Liver biopsy specimens were fixed in buffered formalin and embedded in paraffin. Tissue sections were stained with hematoxylin-eosin, Masson's trichrome, reticulin and Perls' Prussian blue. Each biopsy was read blindly by one experienced pathologist (L.C.C. Gayotto). NASH was graded 1 to 4 according to steatosis intensity (the percentage of hepatocytes with fat vacuoles), necroinflammatory injury and architectural damage. Architectural damage grade 4 was assigned to cirrhosis. The presence of iron pigments was assessed in Kupffer cells, lobular hepatocytes and periportal regions, and graded from 0 to 4 on a semiquantitative basis for each deposition site as follows: 0 , absence of iron; 1, presence of iron at minimum intensity; 2 and 3 , presence of iron at intermediate intensity, and 4, presence of iron at maximum intensity.

All patients but one were tested for both C282Y and H63D mutations. Genomic DNA was extracted from peripheral blood leukocytes by standard techniques, and mutation analyses were carried out as described (17). DNA amplification was performed by the polymerase chain reaction with the primers 5'-CTC.AGG.CAC.TCC.TCT.CAA.CC-3' and 5'-TGG.CAA.GGG.TAA.ACA.GAT. CC-3' for the G845A locus codon 282 and 5'GCC.ACA.TCT.GGC.TTG.AAA.TT-3' and 5'-ACA.TGG.TTA.AGG.CCT.GTT.GC-3' for the $\mathrm{C} 187 \mathrm{G}$ locus codon 63 , which was followed by restriction fragment length polymorphism analysis with the $S n a \mathrm{BI}$ and $B c l \mathrm{I}$ enzymes, respectively.

\section{Statistical analysis}

Statistical analysis was performed using the unpaired Student $t$-test or the Fisher exact test when appropriate. Continuous vari- ables are reported as means \pm SD and categorical variables as frequency or percentage.

\section{Results}

As shown in Table 1, in this cohort of 32 patients, age ranged from 32 to 76 years, average 49.2 years. Ethnic origin was as follows: $72 \%$ Caucasians, 12\% Mulattoes and $12 \%$ Asians. Fifty-nine percent of patients were females, 50\% obese, 53\% hyperlipidemic and $31 \%$ diabetic type 2 . Other clinical features were the continuous use of amiodarone and the daily inhalation of industrial substances for at least six months.

Serum alanine aminotransferase was increased in 30 patients $(93.5 \%)$, and the highest value was 4.8 times the upper normal limit (average $2.42 \pm 1.12$ ). Serum iron concentration was normal $(50-150 \mu \mathrm{g} / \mathrm{dl})$ in $93.5 \%$, average $99.4 \pm 31.3 \mathrm{~g} / \mathrm{dl}$. Transferrin iron saturation was within the normal range (20-40\%) in 68.7\%, average $33.1 \pm 12.7 \%$. Ferritin level was normal (females: 25-250 $\mu \mathrm{g} / \mathrm{dl}$; males: $50-500 \mu \mathrm{g} / \mathrm{dl}$ ) in $78.1 \%$ of women, average $219.8 \pm 163.8 \mu \mathrm{g} / \mathrm{dl}$ and in $76.9 \%$ of men, average $444.8 \pm 305.9 \mu \mathrm{g} / \mathrm{dl}$.

Table 1. Clinical and demographic characteristics of the 32 patients in the present study.

\begin{tabular}{lc}
\hline Variable & Characteristics \\
\hline Age & $49.2 \pm 17.2$ \\
Females & $19(59 \%)$ \\
Ethnic origin & \\
Caucasian & $23(72 \%)$ \\
Mulatto & $4(12 \%)$ \\
Asian & $4(12 \%)$ \\
Others & $1(3 \%)$ \\
Clinical features & \\
Obesity & $16(50 \%)$ \\
Hyperlipidemia & $17(53 \%)$ \\
Diabetes mellitus type 2 & $10(31 \%)$ \\
Nonobese, nonhyperlipidemic and nondiabetic & $7(22 \%)$ \\
Amiodarone use & $2(6 \%)$ \\
Industrial substance inhalation & $3(9 \%)$ \\
\end{tabular}

Data are reported as number of patients with percent in parentheses, except for age which is reported as mean $\pm S D$ in years. 
The histopathological study revealed steatosis grade 2 in 5 cases (15.6\%), grade 3 in $20(62.5 \%)$ and grade 4 in $7(21.9 \%)$. Necroinflammatory injury was grade 1 in 13 cases $(40.6 \%)$, grade 2 in $5(6.3 \%)$, grade 3 in $12(37.5 \%)$, and grade 4 in $2(15.6 \%)$. Ten patients $(31.2 \%)$ had architectural damage grades 1,2 and 3; the remaining two patients were already cirrhotic, with grade 4 damage $(6.3 \%)$.

Liver biopsies submitted to Perls' staining revealed siderosis in only three patients, all of whom were males. The first one, an obese and hyperlipidemic Caucasian, had siderosis grade 2 in both lobular hepatocytes and Kupffer cells. The second patient was a diabetic Asian and presented siderosis grade 1 in lobular hepatocytes and grade 3 in Kupffer cells. The third one, a Caucasian without any associated condition, presented grade 1 siderosis homogeneously distributed in the periportal region, lobular hepatocytes and

\begin{tabular}{|c|c|c|}
\hline & $\begin{array}{l}\text { With hepatic } \\
\text { siderosis }(N=3)\end{array}$ & $\begin{array}{l}\text { Without hepatic } \\
\text { siderosis }(N=29)\end{array}$ \\
\hline Female:male & $0: 3$ & 19:10 \\
\hline \multicolumn{3}{|l|}{ Biochemical profile } \\
\hline Alanine aminotransferase (xNL) & $2.06 \pm 0.29$ & $2.46 \pm 1.17$ \\
\hline Iron $(\mu \mathrm{g} / \mathrm{dl})$ & $134.33 \pm 43.19$ & $95.83 \pm 28.41$ \\
\hline Transferrin saturation (\%) & $44.33 \pm 11.01$ & $33.1 \pm 12.7$ \\
\hline Ferritin (male) $(\mu \mathrm{g} / \mathrm{dl})$ & $764.33 \pm 487.64$ & $348.9 \pm 166.36^{*}$ \\
\hline Ferritin (female) ( $\mu \mathrm{g} / \mathrm{dl})$ & - & $219.8 \pm 163.8$ \\
\hline \multicolumn{3}{|l|}{ Histopathological profile } \\
\hline \multicolumn{3}{|l|}{ Necroinflammatory activity } \\
\hline mild (grades 1 and 2) & 3 & 17 \\
\hline severe (grades 3 and 4) & 0 & 12 \\
\hline \multicolumn{3}{|l|}{ Architectural damage } \\
\hline mild (grades 1 and 2) & 3 & 19 \\
\hline severe (grades 3 and 4 ) & 0 & 10 \\
\hline \multicolumn{3}{|l|}{ HFE mutations $(\mathrm{m} / \mathrm{T})$} \\
\hline $\mathrm{C} 282 \mathrm{Y}+/-$ & $0 / 3$ & $1 / 28$ \\
\hline $\mathrm{H} 63 \mathrm{D}+/-$ & $1 / 3$ & $6 / 28$ \\
\hline $\mathrm{H} 63 \mathrm{D}+/+$ & $0 / 3$ & $1 / 28$ \\
\hline
\end{tabular}

m: carriers of the mutation; T: total number of subjects studied; $x N L$ : number of times the upper limit of the normal range. Biochemical data are reported as means \pm SD. ${ }^{*} \mathrm{P}=0.01$ compared to patients with hepatic siderosis (Fisher exact test).
Kupffer cells.

Of the 31 patients whose DNA was obtained, one was $\mathrm{C} 282 \mathrm{Y}+/-$, seven $\mathrm{H} 63 \mathrm{D}+/$ and one $\mathrm{H} 63 \mathrm{D}+/+$. There were no $\mathrm{C} 282 \mathrm{Y}+/+$ or compound $\mathrm{C} 282 \mathrm{Y} / \mathrm{H} 63 \mathrm{D}$ heterozygotes. The allelic frequencies found in this cohort of patients for $\mathrm{C} 282 \mathrm{Y}$ and $\mathrm{H} 63 \mathrm{D}$ were 1.6 and $14.1 \%$, respectively. Among the three patients with liver siderosis, only one (an obese and hyperlipidemic Caucasian) had an HFE mutation, H63D +/-. The patient who had the H63D +/+ mutation was an obese, hyperlipidemic female with hyperferritinemia, but with no hepatic iron deposition.

The biochemical, histopathological and genetic profile of NASH patients was compared according to the presence or absence of siderosis in liver tissue (Table 2). Patients with hepatic iron overload had significantly higher levels of serum ferritin $(\mathrm{P}<0.05)$; however, there was no statistically significant correlation of hepatic iron overload with necroinflammatory injury or with $H F E$ mutation frequencies.

\section{Discussion}

In our cohort of 32 patients there was no evidence of the association between NASH and hepatic iron overload suggested in recent publications $(7,14,15,18)$. Siderin pigment in liver tissue was not significant in frequency or intensity by Perls' staining. The HFE gene mutation frequencies were compatible with the characteristics of the local general population (19).

Hyperferritinemia was found in less than a quarter of our patients, in contrast to the majority of the patients reported by the French group from Rennes $(18,20,21)$. According to the cited authors, the phenomena of hyperferritinemia, normal transferrin saturation and hepatic siderosis were predominant in patients with NASH and insulin resistance syndrome. Insulin resistance syndrome was defined by the presence of one or more of the following features: obesity, hyperlipidemia 
and abnormal glucose metabolism. In the present study, however, only 9 (36\%) of the 25 patients with insulin resistance syndrome had hyperferritinemia but no hepatic iron overload. In contrast, three patients with hepatic iron overload had significantly higher ferritin levels and two of them had insulin resistance syndrome. This divergence could be partially attributed to the difference between the databases: the patients reported by the cited investigators were selected among subjects with hepatic iron overload, while ours were from the population routinely attended at a Gastroenterology Outpatient Clinic. Since hepatic steatosis, insulin resistance syndrome and iron overload can occur independently or in combination, the hypothesis that postulates insulin resistance as the pivotal abnormality leading to iron overload and subsequently to steatohepatitis (20) is acceptable for the subgroup affected by all of these conditions. This narrows down our population to only two subjects.

The predominant profile of our NASH patients agrees with that reported by Younossi et al. (22) for patients from Cleveland, $\mathrm{OH}$, USA. These authors did not observe significant iron accumulation in cases with nonalcoholic fatty liver, including those with NASH. They carefully excluded alcoholism, by defining $20 \mathrm{~g}$ as the upper limit of acceptable daily ethanol consumption by reviewing the charts and following up patients when necessary. Our criteria were similarly strict about this aspect, a fact that could explain the scarcity of iron deposition also in our cohort, since alcohol induces secondary iron overload.

The absence of Africans and the same proportion of Mulattoes and Asians (12\%) with NASH was conspicuously different from the ethnic distribution of the local population, described as $6.7,28.4$ and $0.5 \%$, respectively, according to Brazilian government statistics in 1999 and referring to the southeast region of the country (http:// www 1.ibge.gov.br/english/estatistica/ populacao/condicaodevida/indicadoresminimos/ tabela1.shtm\#a112). The interpretation of the ethnic profile of Brazilians is more difficult because of the intense pluriracial mixing which has been taking place in the last five centuries, involving natives, Africans, Caucasians and others (23). To our knowledge, patients of African origin having NASH have not been reported in the literature, and the lower proportion of Mulattoes suggests that an ethnically related protective effect might need to be investigated. The higher proportion of Asians in our NASH population could be attributed to the alcohol intolerance genetically determined among them (24), facilitating the determination of alcohol consumption. All Asians were of Japanese origin and all of them had glucose intolerance. Interestingly, it is known that western acculturation increases the frequency of diabetes among the Japanese (25). Since NASH patients in Japan are not excessively diabetic (26), an eventual major susceptibility to developing liver alterations secondary to a glucose intolerance condition might be further studied in this group.

Three patients, two of whom were hypercholesterolemic, had been continuously exposed to fumes while working in a steel factory. They were neither obese nor diabetic, nor did they have any hepatic iron overload. Even though the occupational etiology was not established in this study, Cotrim et al. (27) have already demonstrated in Brazil that chronic exposure to volatile petrochemical products can lead to NASH. Others have also recognized the association between environmental toxicity and NASH $(8,28)$.

Another patient who did not have any of the clinical conditions associated with NASH had been submitted to an extensive enterectomy ten years before because of an abdominal trauma, and had developed short bowel syndrome, that had been well compensated for in the last eight years. Experimental studies using animal models have demonstrated 
that this kind of surgery leads to an increase in permeability of the remaining bowel (29) and bacterial translocation (30). These phenomena could be related to the absorption of endotoxins and bacterial lipopolysaccharides, increasing TNF- $\alpha$ levels and finally leading to steatohepatitis (31).

The allelic frequencies of C282Y (1.6\%) and H63D (14.5\%) observed among Brazilian NASH patients were compatible with those described for the local population: $\mathrm{C} 282 \mathrm{Y}$ allelic frequency ranges from 1.1 to $1.4 \%$ and H63D allelic frequency from 6.4 to $20.3 \%$ according to the population groups analyzed (19). Only one of the three subjects with hepatic iron deposition carried an HFE mutation (H63D +/-). Moreover, it is known that hereditary hemochromatosis and $H F E$ mutations are almost absent among Japanese people (26), although they were well represented in our NASH series. These findings provide evidence that HFE mutations are not necessarily involved in NASH pathogenesis, although they seem to play an important role in Australian and North American Caucasians $(8,14,15)$.

For those populations with high allelic frequencies of $H F E$ mutations, secondary hepatic iron overload might determine oxidative stress and inflammation. In Brazil, however, NASH patients comprise a heterogeneous group with many associated conditions such as hyperinsulinism, environmental hepatotoxin exposure and drugs - but not hepatic iron overload, and their disease susceptibility could be related to genetic and environmental features other than HFE mutations.

\section{Acknowledgments}

The authors would like to thank Ms. Lusane Leão Baía for statistical analysis of the results. Special thanks are due to Dr. Cláudia Tani, Dr. Roseneli D'Este and Ms. Sylvia Assumpção for their contributions to this study.

\section{References}

1. Ludwig J, Viggiano TR, McGill DB \& Ott BJ (1980). Nonalcoholic steatohepatitis. Mayo Clinic Experiences with a hitherto unnamed disease. Mayo Clinic Proceedings, 55: 434-438.

2. James OF \& Day CP (1998). Nonalcoholic steatohepatitis (NASH): a disease of emerging identity and importance. Journal of Hepatology, 29: 495-501.

3. Itoh S, Yougel T \& Kawagoe K (1987). Comparison between nonalcoholic steatohepatitis and alcoholic hepatitis. American Journal of Gastroenterology, 82: 650-654.

4. Diehl AM, Goodman Z \& Ishak KG (1988). Alcohol-like disease in nonalcoholics. A clinical and histologic comparison with alcoholinduced liver injury. Gastroenterology, 95: 1056-1062.

5. Powell EE, Cooksley WGE, Hanson R, Searle J, Halliday JW \& Powell LW (1990). The natural history of nonalcoholic steatohepatitis: a follow-up study of forty-two patients for up to 21 years. Hepatology, 11: 74-80.

6. Lee RG (1989). Nonalcoholic steatohepatitis: a study of 49 patients. Human Pathology, 20: 594-598.

7. Bacon BR, Farakvash MJ, Janney CG \& Neuschwander-Tetri BA (1994). Nonalcoholic steatohepatitis: an expanded clinical entity. Gastroenterology, 107: 1103-1109.

8. Lonardo A, Bellini M, Tondelli E, Frazzoni M, Grisendi A, Pulvirenti M \& Della-Casa G (1995). Nonoalcoholic steatohepatitis and the "bright liver syndrome": should a recently expanded clinical entity be fur- ther expanded? (Letter). American Journal of Gastroenterology, 90: 2072-2074

9. Propst A, Propst T, Judmaier G \& Vogel W (1995). Prognosis in nonalcoholic steatohepatitis. Gastroenterology, 108: 1607.

10. James O \& Day C (1999). Nonalcoholic steatohepatitis: another disease of affluence. Lancet, 353: 1634-1636.

11. Feder JN, Gnirke A, Thomas W et al. (1996). A novel MHC class Ilike gene is mutated in patients with hereditary haemochromatosis. Nature Genetics, 13: 399-408.

12. Adams PC (1999). Population screening for hemochromatosis. Hepatology, 29: 1324-1327.

13. Gochee PA, Powell LW, Cullen DJ, Sart DD, Rossi E \& Olynyk JK (2002). A population-based study of the biochemical and clinical expression of the H63D hemochromatosis mutation. Gastroenterology, 122: 646-651.

14. George DK, Goldwurm S, MacDonald GA, Cowley LL, Walker NI, Ward PJ, Jazwinska EC \& Powell LW (1998). Increased hepatic iron concentration in nonalcoholic steatohepatitis is associated with increased fibrosis. Gastroenterology, 114: 311-318.

15. Bonkovsky HL, Jawaid Q, Tortorelli K, Leclair P, Cobb J, Lambrecht RW \& Banner BF (1999). Nonalcoholic steatohepatitis and iron: increased prevalence of mutations of the HFE gene in nonalcoholic steatohepatitis. Journal of Hepatology, 31: 421-429.

16. Bonkovsky HL, Zivny J, Tortorelli K, Liu Q \& Lambrecht RW (2000). 
Nonalcoholic steatohepatitis with iron: part of insulin resistanceassociated hepatic iron overload? (Letter). Journal of Hepatology, 33: 1025-1026.

17. Datz C, Lalloz MRA, Vogel W et al. (1997). Predominance of the HLA-H Cys282Tyr mutation in Austrian patients with genetic haemochromatosis. Journal of Hepatology, 27: 773-779.

18. Mendler M, Turlin B, Moirand R, Jouanolle A, Sapey T, Guyader D, Le Gall J, Brissot P, David V \& Deugnier Y (1999). Insulin resistanceassociated hepatic iron overload. Gastroenterology, 117: 1155-1163.

19. Agostinho MF, Arruda VR, Basseres DS, Bordin S, Soares MCP, Menezes RC, Costa FF \& Saad STO (1999). Mutation analysis of the HFE gene in Brazilian populations. Blood Cells, Molecules, and Diseases, 25: 324-327.

20. Guillygomarc'h A, Mendler MH, Moirand R, Jouanolle AM, David V \& Deugnier $Y$ (2000). HFE mutations in insulin resistance-associated hepatic iron overload (Letter). Journal of Hepatology, 33: 515516.

21. Moirand $R$, Mendler $M H$, Guillygomarc'h A, Brissot $P$ \& Deugnier $Y$ (2000). Nonalcoholic steatohepatitis with iron: part of insulin resistance-associated hepatic iron overload? (Letter). Journal of Hepatology, 33: 1024-1026.

22. Younossi ZM, Gramlich T, Bacon BR, Matteoni CA, Boparai N, O'Neill RO \& McCullough AJ (1999). Hepatic iron and nonalcoholic fatty liver disease. Hepatology, 30: 847-850.

23. Alves-Silva J, da Silva-Santos M, Guimarães PE, Ferreira AC, Bandelt HJ, Pena SD \& Prado VF (2000). The ancestry of Brazilian mtDNA lineages. American Journal of Human Genetics, 67: 444-461.
24. Lumeng L \& Crabb DW (1994). Genetic aspects and risk factors in alcoholism and alcoholic liver disease. Gastroenterology, 107: 572578.

25. Franco LJ (1996). Diabetes in Japanese-Brazilians - influence of the acculturation process. Diabetes Research and Clinical Practice, 34 (Suppl): S51-S57.

26. Ueno T, Sugawara H, Sujaku K, Hashimoto O, Tsuji R, Tamaki S, Torimura T, Inuzuka S, Sata M \& Tanikawa K (1997). Therapeutic effects of restricted diet and exercise in obese patients with fatty liver. Journal of Hepatology, 27: 103-107.

27. Cotrim HP, Andrade ZA, Parana R, Portugal ML, Lyra LG \& Freitas LAR (1999). Nonalcoholic steatohepatitis: a toxic liver disease in industrial workers. Liver, 19: 299-304.

28. Neuschwander-Tetri BA \& Bacon BB (1996). Nonalcoholic steatohepatitis. Medical Clinics of North America, 80: 1147-1166.

29. Vazquez CM, Molina MT \& Ilundain A (1988). Distal small bowel resection increases mucosal permeability in the large intestine. Digestion, 40: 168-172.

30. Schimpl G, Feierl G, Linni K, Uitz K, Ozbey H \& Hollwarth ME (1999). Bacterial translocation in short-bowel syndrome in rats. European Journal of Pediatric Surgery, 9: 224-227.

31. Wigg AJ, Roberts-Thomson IC, Dymock RB, McCarthy PJ, Grose $\mathrm{RH} \&$ Cummins AG (2001). The role of small intestinal bacterial overgrowth, intestinal permeability, endotoxaemia, and tumour necrosis factor alpha in the pathogenesis of nonalcoholic steatohepatitis. Gut, 48: 206-211. 